\title{
Peritoneal fetus and tubal placentation: A case report of an abdominal pregnancy
}

\author{
Alka Singh, Paban Sharma \\ Dept of Obstetrics \& Gynaecology, Patan Hospital, Kathmandu
}

\begin{abstract}
Reported here is a silent case of an abdominal pregnancy with fetal demise at twenty one weeks gestation, extracted from the peritoneal cavity at laparotomy along with the removal of placenta contained in fallopian tube by salphingectomy without any effort.
\end{abstract}

Key words: intra-uterine fetal demise, abdominal fetus, placenta

\section{Introduction}

Abdominal pregnancy is rare and represents 1.2-1.3\% of all ectopic pregnancies from two institutions in Nepal. ${ }^{1-2}$ The detection has been as early near as $12-13$ weeks in stable condition or in shock from severe intraperitoneal bleed at around mid pregnancy. ${ }^{3-5}$ Occasional abdominal pain and bleeding being the presentation in some cases. ${ }^{6}$

It is usually a medical emergency when it ruptures leading to hemoperitoneum. ${ }^{4-5}$ But in the following case that is described below, abdominal pregnancy was diagnosed at an anomaly scan and was also managed in routine operating day, operation being as simple as can be, whole of the placenta was contained within one of the fallopian tube.

\section{Case}

Mrs. SM, 32 years of age, presented in Patan Hospital on October 14, 2006 with ultrasound diagnosis of abdominal pregnancy at 21 weeks on routine scan. She had been married for 16 years and had been trying to conceive all this time. All the infertility workouts were normal. She also gave history of successful treatment for abdominal tuberculosis ten years back. On general physical examination nothing significant was observed. On abdominal examination a mass corresponding to 20 to 22 weeks gestational uterus with presence of fetal heart sound was found. Bimanual pelvic examination revealed a normal sized freely mobile uterus and an irregular mass with ill defined borders. The ultrasound report showed a single, extra uterine fetus approximately 21 weeks size with presence of cardiac activity and fetal movements. There was crowding of the fetal parts in right lower quadrant with an inhomogeneous mass of $13.9 \times 9.7 \mathrm{~cm}$ in right parauterine region, probably placental tissues, and the uterus measured $12 \times 5 \times 5.8 \mathrm{~cm}$. With these findings sonographic diagnosis was secondary abdominal pregnancy.

Full counseling was done to the patient and patient's husband about the condition and time was given to them to come to terms with the situation. The patient was admitted in the hospital for observation of complications and intervention if and when required. Intrauterine fetal death occurred on fifth day of admission and hence the need for surgery and the possibility of hysterectomy was explained to the patient and family.

Laparotomy was carried out through an infra-umbilical midline incision with cross matched blood ready at hand in case of emergency transfusion. The findings at laparotomy were as follows: - haemoperitoneum was absent, left tube and ovary was normal, right tube containing the placenta formed a mass about $12 \times 10$ $\mathrm{cm}$, free from the surroundings and devoid of adhesions. Female baby was lying in the right para-colic gutter (Fig 1) without any signs of life.

\section{Correspondence}

Dr Alka Singh, MD.

Email: singhalka@hotmail.com 


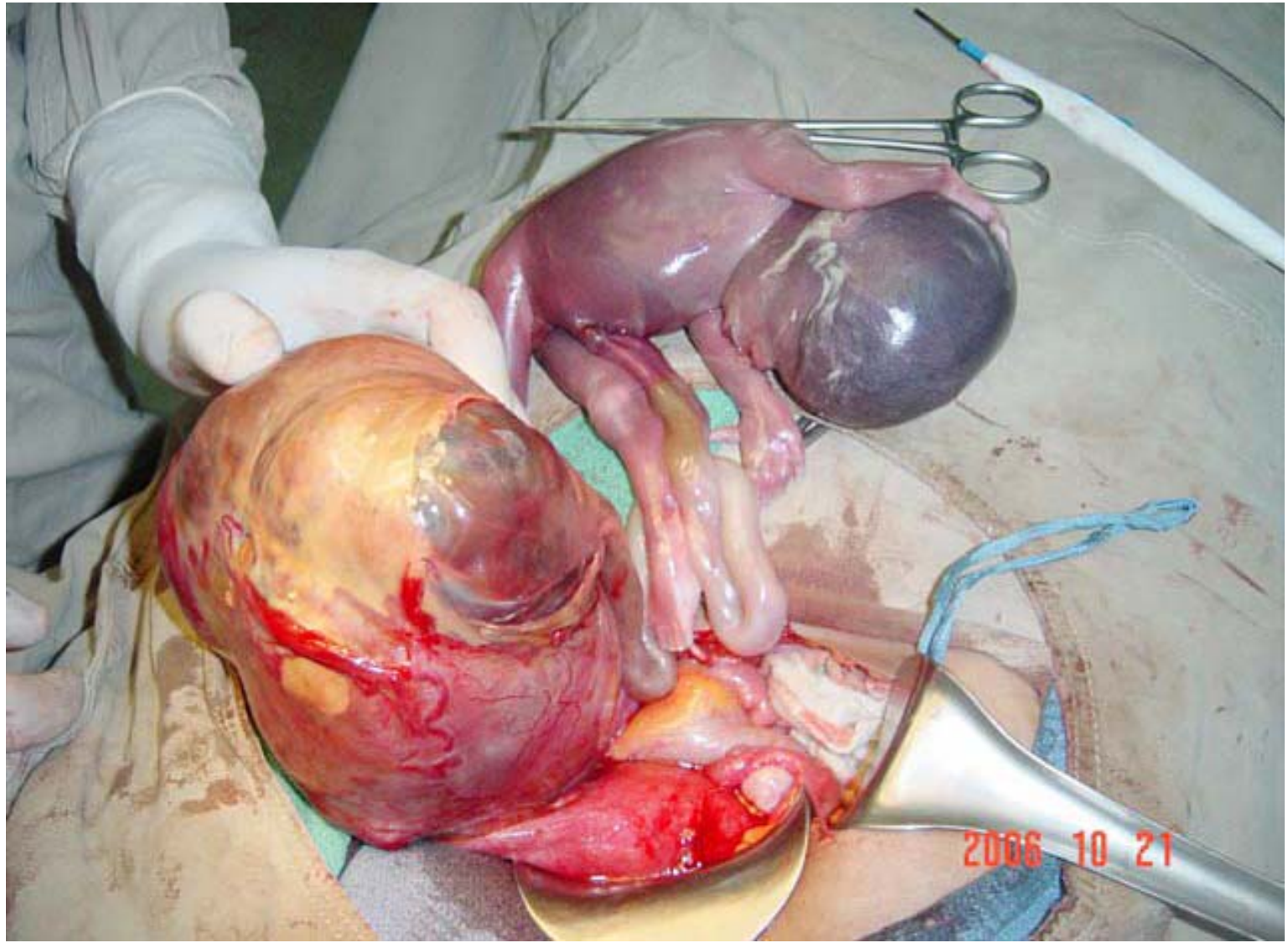

Fig 1: Uterus and the placenta with the fetus lying in the abdominal cavity

Dead fetus was removed out of the abdomen and right salpingo-oopherectomy was carried out to remove the placenta occupied within the tube (Fig 2). The procedure was without any complications and blood loss was approximately $300 \mathrm{ml}$ therefore neither transfusion nor a hysterectomy was required. The post-operative period was uneventful and the patient was discharged on the seventh post-operative day.

\section{Discussion}

From this case it is learnt that the ultrasound diagnosis of abdominal pregnancy is not that difficult if the fetus is positioned very high up and does not have uterine wall around it. While cardiovascular collapse and pain from intraperitoneal bleeding makes the clinical diagnosis easier to move on with hurried intervention like splenectomy (for fetus positioned in spleen).? Whereas silent exceptional cases like this may impart difficult clinical diagnosis unless the normal uterus, devoid of Braxton Hicks contractions is displaced further away by a mass that in true sense constitutes irregular fetal parts. Veiled cases have ended in a lithopedian needing laparoscopic removal. ${ }^{8}$
Primary implantation of the fertilized ovum on the peritoneal cavity is very rare. It is almost always secondary where the conceptus extrudes through a rent from the primary site such as tube, ovary or even uterus. In this case, may be there was a tubal abortion of fetus with the further development of placenta within in the fallopian tube. It may sound unreal but it is true, that even the development of fetus up to term has taken place inside a fallopian tube. ${ }^{9}$ In this case; placenta located inside the fallopian tube made its management sufficient only by salphingectomy otherwise placental removal usually is an uneasy affair. ${ }^{10}$

There is history of maternal and fetal benefit from term delivery. ${ }^{11} \mathrm{Had}$ the baby been alive, in a silent case like this, an expectant management could have been contemplated as others have done for fetus e" 24 weeks gestation. ${ }^{12}$ This allocates time for further fetal growth and development until the woman is ready for abdominal delivery. But because of fetal death which has an incidence of $40-95 \%$, had to be taken for laparotomy. ${ }^{13}$ 


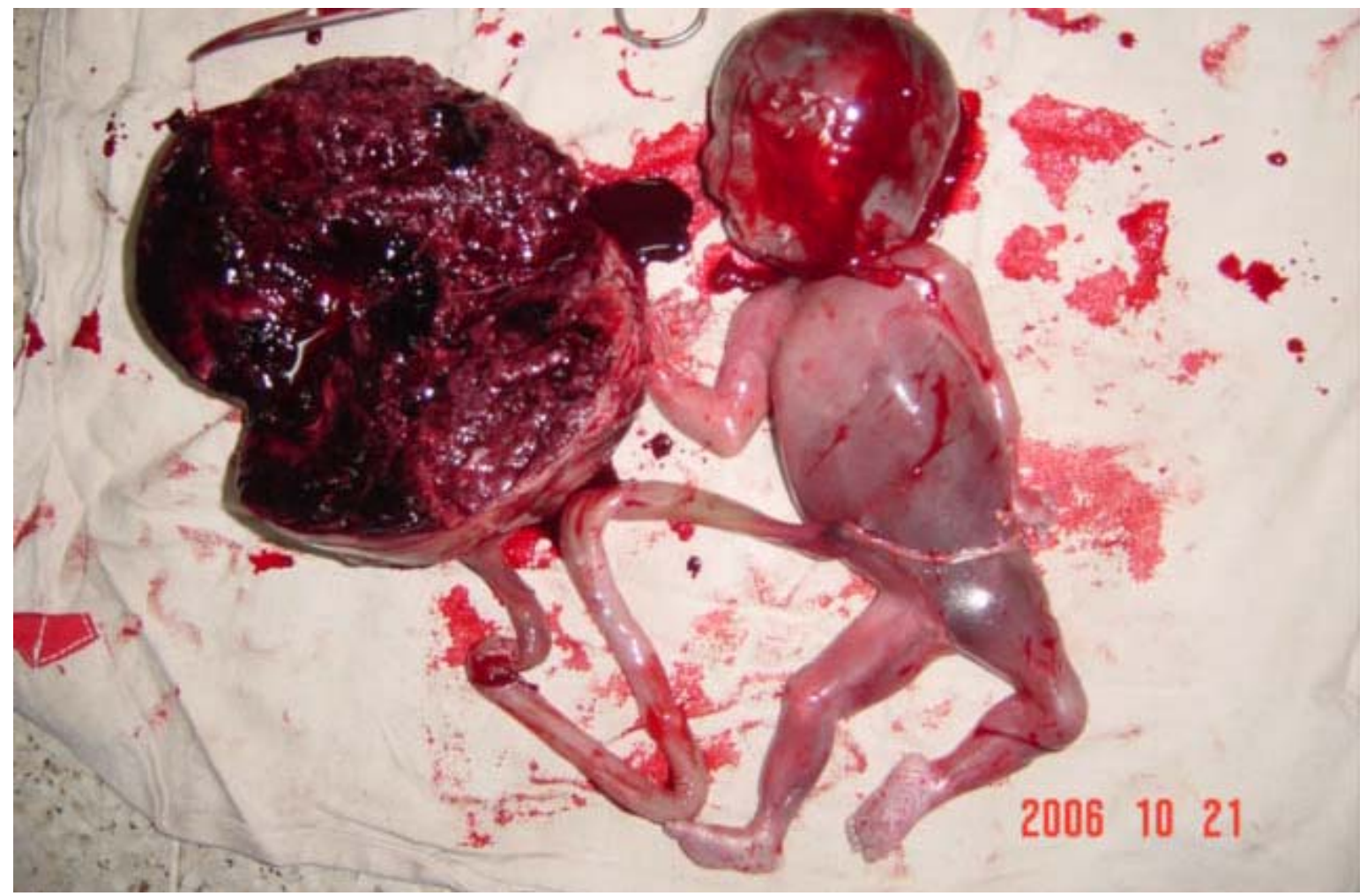

Fig 2: The fetus and the cut section of the fallopian tube showing placenta

\section{Conclusions}

Abdominal pregnancy is a rare entity and silent varieties are rarer where a proper prenatal diagnostic technique allows adequate preparation and optimal surgical management for placenta occupying a fallopian tube.

\section{References}

1. Poonam, Uprety D, Banerjee B. Ectopic pregnancy - two years review from BPKIHS, Nepal. KUMJ. 2005 Oct-Dec; 3(4):365-9

2. Rana A, Gurung G, Singh M, Pradhan N Delayed management of ruptured ectopic pregnancy: an observation of concern. Journal of the Institute of Medicine 1999; 21 (1): 33

3. Rana A, Gurung G, Pradhan N, Singh M. Ectopic pregnancy over a decade JSSN 2001. 4 (1), 24-28

4. Rana A, Singh M. Advanced secondary abdominal pregnancy. Journal of Institute of Medicine 1998. 20 (3 \& 4): 239-242.

5. Jain R C. Abdominal ectopic pregnancy. Journal of Institute of Medicine 2000; 22 (3)

6. Padhye S. Secondary abdominal pregnancy. J Obst of Medicine 1982; 4 (1): 73-80.
7. Aguh CJ, Salihu HM, Buckley A, Imegwu O, Ryave S, Yang RS, Stanford B, Vintzileos AM. Acute abdomen with bones in the spleen. Arch Gynecol Obstet. 2007 Apr 12.

8. Burger NZ, Hung YE, Kalof AN, Casson PR. Lithopedion: laparoscopic diagnosis and removal. Fertil Steril. 2007 May; 87(5):1208-9. Epub 2007 Feb 6.

9. Huang SC, 7. Hsu TY. Term tubal pregnancy with a live born and healthy baby. Pediatr Dev Pathol. 2007 Jan-Feb; 10(1):69-71.

10. Godyn JJ, Hazra A, Gulli VM. Subperitoneal placenta accreta succenturiate in the case of a successful near-term extrauterine abdominal pregnancy. Hum Pathol. 2005 Aug; 36(8): 922-6.

11. Ang LP, Tan AC, Yeo SH. Abdominal pregnancy: a case report and literature review. Singapore Med J 2000; 41:454-7.

12. Martin JN Jr, Sessums JK, Martin RU, Pryor JA, Morrison JC. Abdominal pregnancy: Current concepts of management. Obstet Gynecol 1988; 71:549.

13. Rahman MS, al-Suleiman SA, Rahman J. Advanced abdominal pregnancy-observations in 10 cases. Obstet Gynecol 1982; 59:366. 